\title{
Safety, pharmacokinetics, and antitumor properties of anlotinib, an oral multi-target tyrosine kinase inhibitor, in patients with advanced refractory solid tumors
}

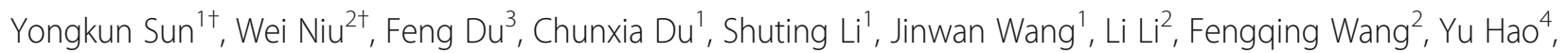
Chuan $\mathrm{Li}^{2^{*}}$ and Yihebali Chi ${ }^{* *}$

\begin{abstract}
Background: Anlotinib is a novel multi-target tyrosine kinase inhibitor that is designed to primarily inhibit VEGFR2/3, FGFR1-4, PDGFR a/ $\beta$, c-Kit, and Ret. We aimed to evaluate the safety, pharmacokinetics, and antitumor activity of anlotinib in patients with advanced refractory solid tumors.

Methods: Anlotinib (5-16 mg) was orally administered in patients with solid tumor once a day on two schedules: (1) four consecutive weeks (4/0) or (2) 2-week on/1-week off (2/1). Pharmacokinetic sampling was performed in all patients. Twenty-one patients were further enrolled in an expanded cohort study on the recommended dose and schedule. Preliminary tumor response was also assessed.

Results: On the 4/0 schedule, dose-limiting toxicity (DLT) was grade 3 hypertension at $10 \mathrm{mg}$. On the 2/1 schedule, DLT was grade 3 hypertension and grade 3 fatigue at $16 \mathrm{mg}$. Pharmacokinetic assessment indicated that anlotinib had long elimination half-lives and significant accumulation during multiple oral doses. The 2/1 schedule was selected, with $12 \mathrm{mg}$ once daily as the maximum tolerated dose for the expanding study. Twenty of the 21 patients (with colon adenocarcinoma, non-small cell lung cancer, renal clear cell cancer, medullary thyroid carcinoma, and soft tissue sarcoma) were assessable for antitumor activity of anlotinib: 3 patients had partial response, 14 patients had stable disease including 12 tumor burden shrinkage, and 3 had disease progression. The main serious adverse effects were hypertension, triglyceride elevation, hand-foot skin reaction, and lipase elevation.
\end{abstract}

Conclusions: At the dose of $12 \mathrm{mg}$ once daily at the 2/1 schedule, anlotinib displayed manageable toxicity, long circulation, and broad-spectrum antitumor potential, justifying the conduct of further studies.

Keywords: Anlotinib, Anti-angiogenesis, Phase I study, Advanced refractory solid tumors, Pharmacokinetics, Safety

\section{Background}

Several molecular pathways play crucial roles in cancer development, including proliferation pathways, cell-cycle control pathways, and the processes of angiogenesis [1,2], where some important mediators have been successfully identified as potential targets for new anticancer

\footnotetext{
* Correspondence: dryihebalichi@126.com; chli@simm.ac.cn

${ }^{\dagger}$ Equal contributors

'Department of Medical Oncology, Cancer Hospital, Chinese Academy of Medical Sciences and PUMC, Beijing 100021, China

${ }^{2}$ The State Key Laboratory of Drug Research, Shanghai Institute of Materia

Medica, Chinese Academy of Sciences, Shanghai 201203, China

Full list of author information is available at the end of the article
}

treatments. Multi-targeted tyrosine kinase inhibitors (TKIs) have demonstrated significant antitumor effects in a variety of tumor types through the inhibition of angiogenetic and proliferative signaling [3-5].

Anlotinib is a novel oral multi-targeted receptor tyrosine kinase inhibitor, which has a broad spectrum of inhibitory action on tumor angiogenesis and growth. The vascular endothelial growth factor (VEGF) isoforms and their receptors (VEGFRs) are crucial proteins in both vasculogenesis and angiogenesis and have been proved as effective anticancer target $[3,5,6]$. In vitro studies using recombinant enzymes indicated that anlotinib selectively 
inhibited VEGFR2/KDR and VEGFR3 approximately 20 and 500 times as potent as sunitinib and sorafenib, respectively (details pending publication elsewhere). On the other hand, dysregulation of fibroblast growth factor (FGF)/fibroblast growth factor receptor (FGFR) axis results in aggressive cancer phenotypes by promoting cancer progression and enhancing the angiogenic potential of tumor microenvironment [7-9]. FGF/FGFR signaling alterations has been connected with chemotherapy resistance and poor clinical outcome [10-13]. Preclinical results showed that anlotinib significantly inactivated FGFR1-4, especially the FGFR2, to a greater extent than sorafenib did.

Anlotinib suppressed tumor cell proliferation via inhibition of platelet-derived growth factor receptors $\alpha / \beta$ (PDGFR $\alpha / \beta)$, c-Kit, Ret as well as Aurora-B, c-FMS, and discoidin domain receptor 1(DDR1), which was a group of newly identified kinase targets involving the tumor progression [14-17]. In addition, anlotinib showed antitumor activity against tumor cells carrying mutations in PDGFR $\alpha$, c-Kit, Met, and epidermal growth factor receptor (EGFR).

In vivo, anlotinib has showed broad activity against human tumor xenograft models of the colon (SW-620), ovarian (SK-OV-3), liver (SMMC-7721), renal (Caki-1), glioma (U87MG), and non-small cell lung (Calu-3) during dosing period.

In Sprague-Dawley rats and beagle dogs, anlotinib was rapidly absorbed from the gastrointestinal tracks after oral administration. The oral bioavailability was $23-45 \%$ in rats and $47-74 \%$ in dogs. In vitro metabolism studies demonstrated that anlotinib was primarily metabolized by cytochrome P450-mediated hydroxylation and dealkylation. The oxidized metabolites were excreted directly into the bile or excreted after conjugation mainly to form glucuronides. Anlotinib exhibited large volume of distribution in both species. In rats, primary tissues, such as the lung, kidneys, liver, and heart, exhibited significant higher exposure levels to anlotinib compared with that in plasma. The exposure level in the brain was comparable with the corresponding plasma level. In tumor-bearing mice, anlotinib concentrated 2.4-2.6 times in tumor tissue than in plasma. Besides, anlotinib exhibited in vitro inhibitory activities against human cytochrome P450 3A4 and 2C9 with half maximum inhibitory concentrations of 0.11 and $0.25 \mu \mathrm{M}$, respectively.

Based on the promising preclinical antitumor activity, safety, and pharmacokinetics data, this phase I clinical study was performed to determine the dose-limiting toxicity (DLT), maximum tolerated dose (MTD), basic pharmacokinetics, dosage regimen recommended for phase II trial, and preliminary antitumor effects of anlotinib in patients with advanced refractory solid tumor.

\section{Methods}

\section{Eligibility criteria}

Patients with pathologically and/or cytologically proven advanced cancer with no standard therapy were included in this study. Eligibility criteria include ages 18-65, ECOG PS $0-1$, and an estimated survival duration of more than 3 months. Patients who had used other chemotherapy drugs need to stop for at least 30 days; patients who had received major surgery needed to rest for at least 4 weeks. Routine blood indices, blood lipids, liver and kidney function, and heart function (left ventricular ejection fraction) are normal; no major organ dysfunction. Patients needed to agree to use and utilize an adequate method of contraception. Patients had to give written informed consent for the study and be willing to comply with criteria of follow-up.

Patients were not eligible if they had the following: brain metastases; spinal cord compression; carcinomatous meningitis; brain or leptomeningeal disease confirmed by CT or MRI examination; urine protein $\geq++$ confirmed by a 24-h urinary protein excretion $>1.0 \mathrm{~g}$; failed to heal wounds or fractures for long term; coagulation abnormalities; experienced arterial or venous thromboembolic events before the first treatment; pre-existing thyroid disease; thyroid function could not be maintained within the normal range under treatment; carried active hepatitis $\mathrm{B}$ or hepatitis C; HIV-positive, acquired or congenital immunodeficiency diseases, or organ transplantation; and serious concomitant diseases.

\section{Study design}

This was a first-in-human, phase I, open-label study of anlotinib in advanced refractory solid tumors. The primary objective was to establish the safety profile of anlotinib by identifying DLT, MTD, the recommended phase II dose, and schedule. Secondary objectives included description of single-dose and multi-dose pharmacokinetics of oral anlotinib and assessment of preliminary antitumor effect.

All patients provided written informed consent. The study protocol and amendments were reviewed and approved by the Institutional Review Board, in accordance with the Declaration of Helsinki.

\section{Treatment}

Those patients received escalating doses of anlotinib daily for (1) four consecutive weeks (4/0) or (2) 2-week on/1-week off (2/1). A standard $3+3$ design was applied, with terms for cohort expansion to six evaluable patients if a DLT (grade 4 blood toxicity or grade 3 neutropenia with fever $\geq 38.5^{\circ} \mathrm{C}$; grade 3 or higher non-hematologic toxicity) was observed in the first cycle of treatment among the initial three patients. If two DLTs were observed during the first cycle in a cohort, dose-escalation 
was halted and dose continued at a lower level until the MTD (the highest dose level for which the incidence of first-cycle DLT was $<33 \%$ ) was identified. In the absence of two or more DLTs in a cohort, the dose was escalated in a modified Fibonacci scheme. Treatment cycles were repeated until disease progression, unacceptable toxicity, or withdrawal of consent.

\section{Assessment}

Efficacies were evaluated according to NCI-proposed Response Evaluation Criteria In Solid Tumors (RECIST 1.1). The tumor will be assessed every two cycles including tumor-related symptoms and physical and imaging examination (CT or MRI) of superficial lesions. Physical and imaging examination of tumor lesions should be done at least four weeks after the first effect evaluation in patients with complete remission (CR), partial remission (PR), and stable disease (SD) to confirm efficacy.

Adverse events are graded into $0-5$ according to the National Cancer Institute Common Terminology Criteria for Adverse Events (NCI-CTCAE 4.0). During treatment, blood pressure will be monitored every day. Patients with unresolved adverse reactions at the end of the test needed to be treated and followed until the reactions returned to the grade 1 degree or less, or stable.

\section{Pharmacokinetic assessments}

In single-dose studies, anlotinib were administered orally at dose of $5,10,12$, or $16 \mathrm{mg}$ anlotinib/person. Serial blood samples were collected in heparinized tubes before and at $0.5,1,2,4,8,11,24,48,72,96,120,144,168$, 192, 216, and $240 \mathrm{~h}$ (samples of 144-240 h were collected only in 12 or $16 \mathrm{mg} /$ person dose group) after dosing. In the $10 \mathrm{mg} /$ person dose group, urine was sampled before and $0-2,2-6,6-11,11-24,24-34,34-48,48-58,58-72$, $72-96$, and $96-120 \mathrm{~h}$ after dosing. In multiple-dose studies, there were two ways of multiple-dose administration. Initially, patients in 5 and $10 \mathrm{mg} /$ person/day groups were treated consecutively for 28 days. Blood samples were collected $24 \mathrm{~h}$ after dosing on days $1,2,4,7,10,13,15,16$, $18,21,24,28$, and 29 . Later, the other volunteers were given multiple doses of anlotinib at 10,12 , or $16 \mathrm{mg}$ anlotinib/person/day in the $2 / 1$ schedule for two cycles. Blood samples were collected $24 \mathrm{~h}$ after dosing on days $1,4,7$, $10,13,15,18,22,29$, and 36 . The collected blood samples were centrifuged to prepare plasma fractions; the urine samples were weighed after collection. All samples were stored at $-70{ }^{\circ} \mathrm{C}$ for subsequent analysis. Concentrations of anlotinib were measured by liquid chromatography/ mass spectrometry.

The maximum concentration $\left(C_{\max }\right)$ and the time taken to achieve $C_{\max }\left(T_{\max }\right)$ were obtained directly from the data with no interpolation. The area under concentrationtime curve up to the last measured time point $\left(\mathrm{AUC}_{0-t}\right)$ was calculated by the trapezoidal rule. The elimination half-life $\left(t_{1 / 2}\right)$ was calculated using the relationship 0.693/ $k$. The $k$ was estimated by linear regression analysis of the terminal portion of the log concentration-time data. The

Table 1 Patient characteristics by anlotinib dose cohort

\begin{tabular}{|c|c|c|c|c|c|c|}
\hline \multirow[t]{3}{*}{ Characteristic } & & \multicolumn{5}{|c|}{ Number of patients } \\
\hline & & \multicolumn{2}{|c|}{ Four consecutive weeks } & \multicolumn{3}{|c|}{ 2-week on/1-week off } \\
\hline & & $5 \mathrm{mg} /$ person & 10 mg/person & 10 mg/person & 12 mg/person & $16 \mathrm{mg} /$ person \\
\hline Total & & 4 & 4 & 3 & 21 & 3 \\
\hline \multirow[t]{2}{*}{ Sex } & Male & 2 & 2 & 2 & 15 & 1 \\
\hline & Female & 2 & 2 & 1 & 6 & 2 \\
\hline \multirow[t]{2}{*}{ Age, year } & Median & 39 & 50 & 60 & 47 & 45 \\
\hline & Range & $21-49$ & $39-60$ & $53-65$ & $32-60$ & $48-55$ \\
\hline \multirow[t]{2}{*}{ ECOG score } & 0 & 0 & 1 & 0 & 9 & 0 \\
\hline & 1 & 4 & 3 & 3 & 12 & 3 \\
\hline \multirow[t]{3}{*}{ Pretreatment } & Surgery & 3 & 4 & 2 & 18 & 2 \\
\hline & Radiotherapy & 2 & 1 & 3 & 6 & 1 \\
\hline & Chemotherapy & 4 & 4 & 3 & 15 & 3 \\
\hline \multirow[t]{6}{*}{ Tumor site } & Sarcoma & 2 & 1 & 1 & 4 & 1 \\
\hline & MTC & 0 & 0 & 0 & 6 & 0 \\
\hline & CC & 1 & 2 & 0 & 0 & 1 \\
\hline & NSCLC & 0 & 0 & 1 & 3 & 0 \\
\hline & $\mathrm{RC}$ & 0 & 0 & 0 & 4 & 0 \\
\hline & Other & 1 & 1 & 1 & 4 & 1 \\
\hline
\end{tabular}


renal clearance $\left(\mathrm{CL}_{\mathrm{R}}\right)$ was calculated by dividing the cumulative amount excreted into urine (Cum. $A_{e-U}$ ) by plasma $\mathrm{AUC}_{0-t}$. Accumulation ratio $\left(R_{\mathrm{ac}}\right)$ was used to indicate the extent of accumulation during multiple doses of anlotinib capsules and calculated using the following equation:

$$
R_{\mathrm{ac}}=C_{24 \mathrm{~h}(\mathrm{Day} 15)} / C_{24 \mathrm{~h}(\text { Day1 })},
$$

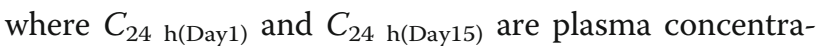
tions of anlotinib at $24 \mathrm{~h}$ after dosing on day 1 and day 15 , respectively. Plasma pharmacokinetic (PK) parameters were determined using noncompartmental method with a Kinetica software package (version 5.0; Thermo Scientific, Philadelphia, PA).

\section{Statistical analysis}

The two-side test is used for all statistical tests. $P \leq 0.05$ is considered as statistical significance. The measurement data will use mean \pm SD or median ( $\min , \max$ ) for statistical description. Compared with baseline data of screening period, use paired $t$ test to compare the difference before/after the treatment within the group. Frequency (constituent ratio) is used for statistical description to the enumeration data. The changes before/after the treatment will use $\chi^{2}$ test (accurate probabilistic method) or nonparametric test.

Table 2 Adverse events of patients in 12 mg/day group (the 2/1 schedule)

\begin{tabular}{|c|c|c|c|c|c|c|c|c|}
\hline \multirow[t]{3}{*}{ Adverse events } & \multicolumn{4}{|l|}{ Grade 1/2 } & \multicolumn{4}{|l|}{ Grade 3} \\
\hline & \multicolumn{2}{|l|}{ First 2 cycles } & \multicolumn{2}{|l|}{ All cycles } & \multicolumn{2}{|l|}{ First 2 cycles } & \multicolumn{2}{|l|}{ All cycles } \\
\hline & No. of patients & $\%$ & No. of patients & $\%$ & No. of patients & $\%$ & No. of patients & $\%$ \\
\hline Occurred at least one time & 21 & 100 & 21 & 100 & 2 & 10 & 6 & 29 \\
\hline Hand-foot skin reaction & 4 & 19 & 10 & 48 & 0 & 0 & 1 & 5 \\
\hline Rash & 4 & 19 & 6 & 29 & 0 & 0 & 0 & 0 \\
\hline Hypertension & 5 & 24 & 5 & 24 & 0 & 0 & 2 & 10 \\
\hline Proteinuria & 5 & 24 & 14 & 67 & 0 & 0 & 0 & 0 \\
\hline Triglyceride elevation & 6 & 29 & 11 & 52 & 1 & 5 & 2 & 10 \\
\hline Total cholesterol elevation & 6 & 29 & 13 & 62 & 0 & 0 & 0 & 0 \\
\hline Hypothyroidism & 8 & 38 & 12 & 57 & 0 & 0 & 0 & 0 \\
\hline Hyperthyroidism & 2 & 10 & 2 & 10 & 0 & 0 & 0 & 0 \\
\hline ALT elevation & 6 & 29 & 10 & 48 & 0 & 0 & 0 & 0 \\
\hline AST elevation & 4 & 19 & 9 & 43 & 0 & 0 & 0 & 0 \\
\hline Creatinine elevation & 1 & 5 & 2 & 10 & 0 & 0 & 0 & 0 \\
\hline Total bilirubin elevation & 5 & 24 & 8 & 38 & 0 & 0 & 0 & 0 \\
\hline Lipase elevation & 1 & 5 & 5 & 24 & 1 & 5 & 1 & 5 \\
\hline Serum amylase & 4 & 19 & 9 & 43 & 0 & 0 & 0 & 0 \\
\hline Myocardial enzymes abnormal & 2 & 10 & 3 & 14 & 0 & 0 & 0 & 0 \\
\hline Leukopenia & 3 & 14 & 6 & 29 & 0 & 0 & 0 & 0 \\
\hline Neutropenia & 0 & 0 & 2 & 10 & 0 & 0 & 0 & 0 \\
\hline Thrombocytopenia & 0 & 0 & 2 & 10 & 0 & 0 & 0 & 0 \\
\hline Hemorrhage & 0 & 0 & 1 & 5 & 0 & 0 & 0 & 0 \\
\hline Urine occult blood & 5 & 24 & 8 & 38 & 0 & 0 & 0 & 0 \\
\hline Fatigue & 5 & 24 & 7 & 33 & 0 & 0 & 0 & 0 \\
\hline Diarrhea & 6 & 29 & 7 & 33 & 0 & 0 & 0 & 0 \\
\hline Hoarseness & 3 & 14 & 5 & 24 & 0 & 0 & 0 & 0 \\
\hline Nausea & 3 & 14 & 3 & 14 & 0 & 0 & 0 & 0 \\
\hline Inappetence & 1 & 5 & 2 & 10 & 0 & 0 & 0 & 0 \\
\hline Toothache & 1 & 5 & 4 & 19 & 0 & 0 & 0 & 0 \\
\hline Pharyngalgia & 1 & 5 & 4 & 19 & 0 & 0 & 0 & 0 \\
\hline Premature beat & 0 & 0 & 1 & 5 & 0 & 0 & 0 & 0 \\
\hline
\end{tabular}




\section{Results}

\section{Patient characteristics}

Thirty-five patients were enrolled in the study between July 2011 and August 2013. Two cohorts of patients received anlotinib at doses ranging from $5 \mathrm{mg}(n=4)$ to $10 \mathrm{mg}(n=4)$ once daily on the $4 / 0$ schedule, and three cohorts of patients at doses of $10 \mathrm{mg}(n=3), 12 \mathrm{mg}(n=$ $21)$, and $16 \mathrm{mg}(n=3)$ once daily on the $2 / 1$ schedule. Patient baseline characteristics are presented in Table 1.

\section{Safety and tolerability}

On the $4 / 0$ schedule, no DLT was observed in the first four patients at the starting dose of $5 \mathrm{mg} /$ day. However, at $10 \mathrm{mg} /$ day, one patient developed grade 3 hypertension among the first three patients treated. An additional patient was enrolled and also developed grade 3 hypertension. Therefore, the further dose escalation was halted. Meanwhile, PK study revealed a continuously significant anlotinib accumulation in patients who received continuous administration (data not shown). Based on the PK profile of anlotinib and the two DLTs observed at the dose of $10 \mathrm{mg} /$ day, we modified the administration protocol from the $4 / 0$ schedule to the $2 / 1$.

On the $2 / 1$ schedule, because none of the three patients experienced DLT at initial doses of $10 \mathrm{mg} /$ day, the dose escalation proceeded to $16 \mathrm{mg} /$ day. Two of the three patients in the $16 \mathrm{mg}$ cohort experienced DLT (one grade 3 fatigue and one grade 3 hypertension). Therefore, the MTD had been exceeded, and the next lower dose of $12 \mathrm{mg} /$ day was further evaluated by entering additional patients. None of the initial three patients experienced grade $3 / 4$ adverse events. On the basis, $12 \mathrm{mg}$ once daily was selected for the expanding study.

A total of 21 patients received the $12 \mathrm{mg} /$ day dose on the $2 / 1$ schedule. During the first 2 cycles, all the patients experienced an adverse event of any causality. All the hematologic toxicities were mild. As illustrated in Table 2, the most common non-hematologic adverse events were hypothyroidism, triglyceride elevation, total cholesterol elevation, ALT elevation, diarrhea, and proteinuria. During the first 2 cycles, a total of two patients (10\%) experienced grade 3 adverse events (one triglyceride elevation and one lipase elevation). During all treatment cycles, there were six patients $(29 \%)$ with grade $3 / 4$ adverse events. The most common $(>5 \%)$ non-hematologic grade 3 adverse events were hypertension, triglyceride elevation, hand-foot skin reaction, and lipase elevation.

\section{Efficacy}

According to the RECIST 1.1 criteria, 19 patients had target lesions and one patient with multiple small lung metastases had non-target lesions. Among the 20 patients whose response can be assessed, 3 patients (15\%) had PR; 14 patients (70 \%) maintained SD including 12
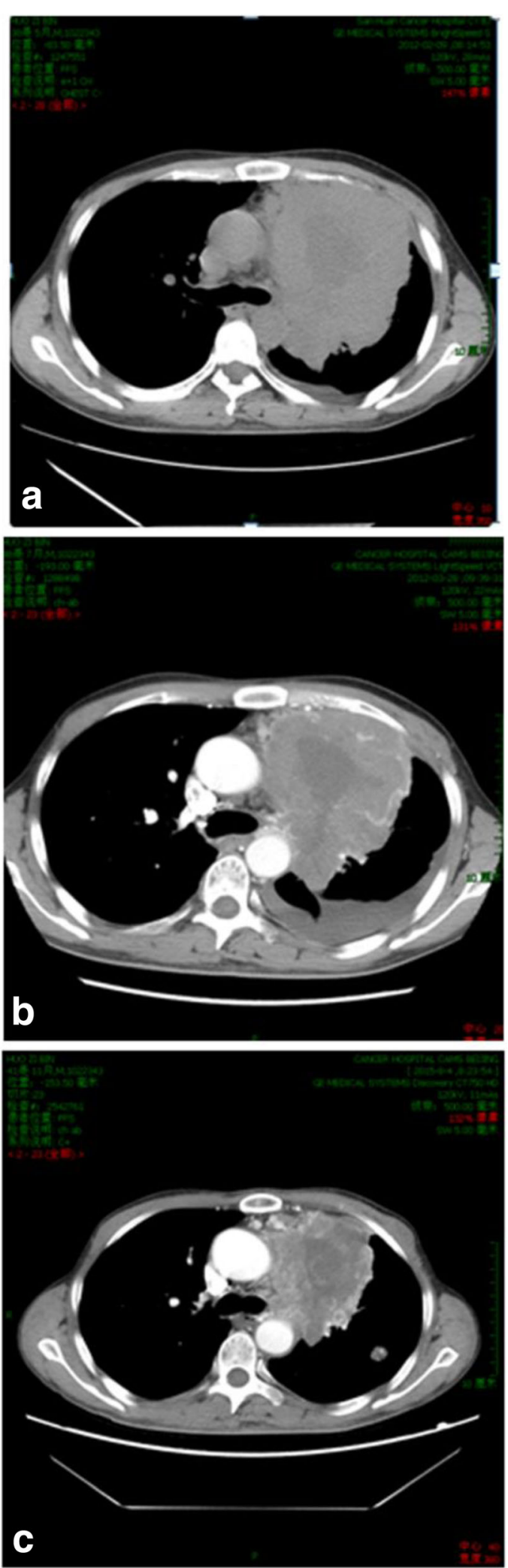

Fig. 1 The lung metastasis changes in patients of alveolar soft tissue sarcoma with lung metastasis during treatment. a Before treatment. b Treatment after 2 cycles (42 days). c Treatment after 3 years 
patients with tumor burden shrinkage, and 3 patients $(15 \%)$ had progressive disease (PD) (Additional file 1: Figure S1). PR was observed in the following tumor type: two renal carcinoma and one soft tissue sarcoma. In the current phase I study, other tumor types that responded to anlotinib included medullary thyroid carcinoma, nonsmall cell lung cancer, colorectal cancer, melanoma, thymic carcinoma, and adenoid cystic carcinoma (Fig. 1).

The median administration duration was 24 weeks. Twenty-four, sixteen, and nine patients had received anlotinib for over 12, 24, and 72 weeks, respectively. Furthermore, the treatment duration had exceeded 100 weeks in three patients (Fig. 2).

\section{Pharmacokinetics}

The mean plasma level-time curve of anlotinib after a single oral administration at $5,10,12$, or $16 \mathrm{mg} /$ subject is shown in Fig. 3. The associated plasma PK parameters are summarized in Table 3. Anlotinib exhibited rapid intestinal absorption. This was indicated by its plasma concentration, which significantly increased at $1 \mathrm{~h}$ after dosing in most patient subjects (Fig. 3). The levels of systemic exposure to anlotinib $\left(C_{\max }\right.$ and $\left.\mathrm{AUC}_{0-120 \mathrm{~h}}\right)$ tended to increase as the dose level increased from $5 \mathrm{mg}$ anlotinib/person to $16 \mathrm{mg}$ anlotinib/person, but the dose proportionality was inconclusive (Table 3). Anlotinib reached its maximum plasma concentration with $T_{\max }$ of 4-11 $\mathrm{h}$ after dosing, then it eliminated slowly with $t_{1 / 2}$ of 64-136 h and MRT of 124-167 h. The renal excretion of anlotinib was poor, with a $\mathrm{CL}_{\mathrm{R}}$ of $0.004 \mathrm{~L} / \mathrm{h} / \mathrm{kg}$; the fraction of the dose excreted into urine $\left(f_{e}-u\right)$ was $\sim 0.9 \%$.

Notably, anlotinib exhibited a quite long $t_{1 / 2}(96 \pm 17 \mathrm{~h})$, which appeared to be dose-independent. The long $t_{1 / 2}$ resulted in significant accumulation of plasma anlotinib over time with a mean $R_{\mathrm{ac}}$ of $12 \pm 7$, suggesting drug accumulation over time (Fig. 3). The trough plasma concentration-time curve of anlotinib after treatment of anlotinib at 10,12 , or $16 \mathrm{mg} /$ subject in the $2 / 1$ schedule is depicted in Fig. 3. A 2-week subchronic dosing brought about continuously increased plasma concentration of anlotinib in patients, while its maximum plasma concentration was reached at day 14. Subsequently, the plasma level of anlotinib was apparently decreased with a 7-day washout until the beginning of the other treatment cycle.

\section{Discussion and conclusions}

This study evaluated the multi-targeted tyrosine kinase inhibitor anlotinib in patients with refractory advanced solid tumors and has met its primary objective of establishing the safety profile of anlotinib and identifying a recommended $2 / 1$ schedule and $12 \mathrm{mg}$-once-daily dose for further investigation in phase II studies.

The toxicity profile of anlotinib was in agreement with that reported in other analogous agents such as sorafenib, sunitinib, and regorafenib [18-20]. The most frequent serious adverse events observed in this study were hand-foot skin reaction, hypertension, fatigue, and lipase elevation. Interestingly, some phase IV studies identified diarrhea as

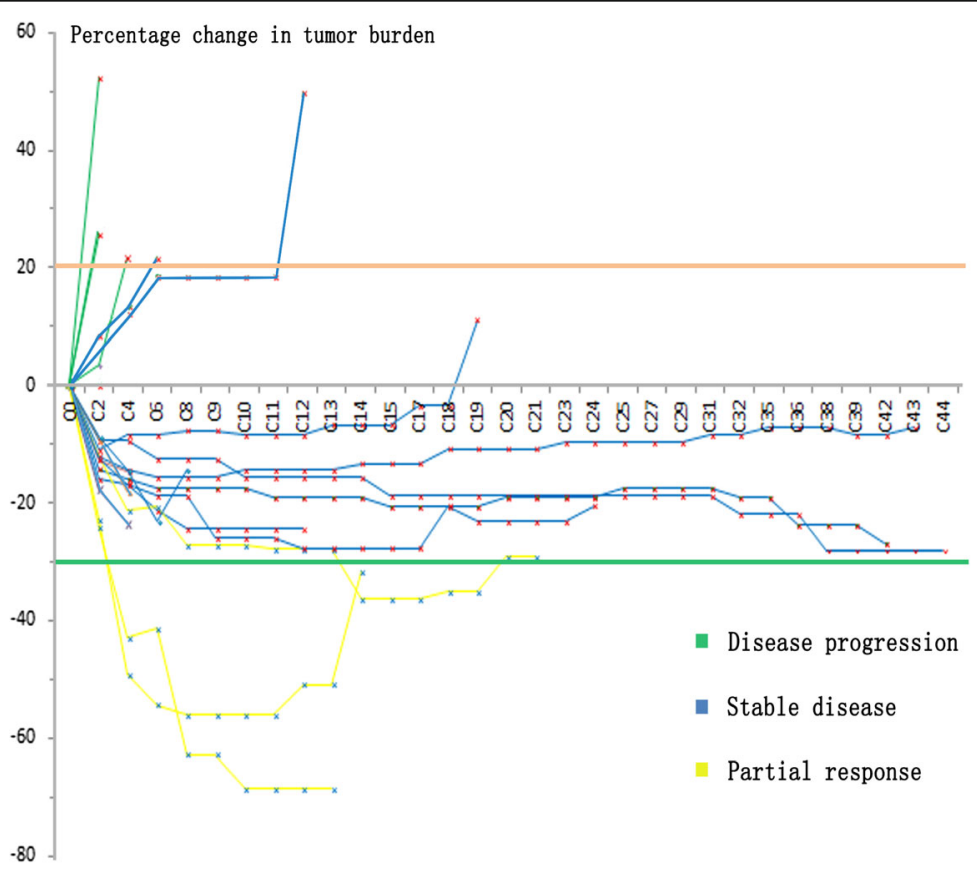

Fig. 2 Duration of treatment and tumor size changes of 20 patients who received $12 \mathrm{mg}$ QD at the 2/1 schedule 

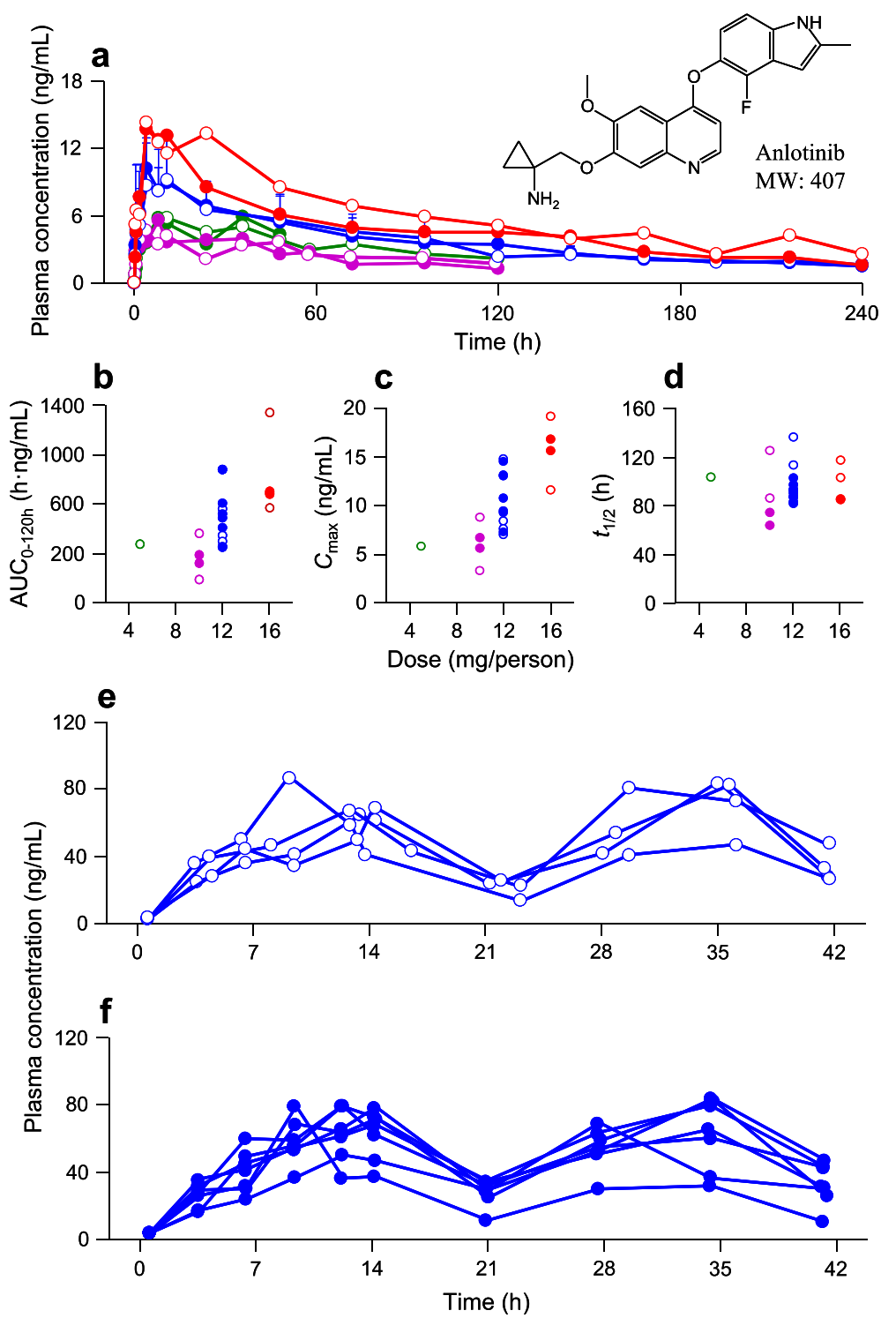

Fig. 3 Plasma concentrations of anlotinib over time after a single oral dose of anlotinib capsules at 5 (green line), 10 (purple line), 12 (blue line), or

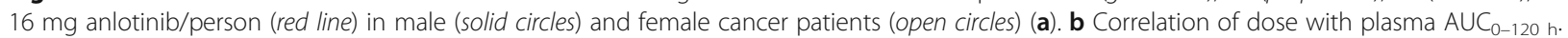
c Correlation of dose with plasma $C_{\max }$. $\mathbf{d}$ Correlation of dose with $t_{1 / 2}$. e Plasma concentrations of anlotinib ( $24 \mathrm{~h}$ after daily dosing) over time during multiple oral doses of anlotinib capsules at $12 \mathrm{mg}$ anlotinib/person/day in female cancer patients. $\mathbf{f}$ Plasma concentrations of anlotinib (24 h after daily dosing) over time during multiple oral doses of anlotinib capsules at $12 \mathrm{mg}$ anlotinib/person/day in male cancer patients

one of the most common serious adverse events in oral anti-VEGFR TKIs [18, 21, 22], but in the present study, $33 \%$ of patients had moderate diarrhea and none developed grade 3 or 4 diarrhea, suggesting the potential of anlotinib in decreasing gastrointestinal toxicity.

In addition, we observed high frequency of triglyceride and cholesterol elevation in this study. Although not resulting in uncomfortable symptoms, they still needed regular monitor because of their close association with arterial thromboembolic event, which was significantly more common in patients receiving anti-VEGFR TKIs [23]. All the adverse events appeared to be manageable even in those patients who received anlotinib for an extended period. Our data supported the close monitor of patients who received anlotinib in terms of lipid and blood pressure status in the following studies.

Although efficacy was not the primary endpoint of phase I study, the tumor response data suggested a substantial and broad antitumor activity of anlotinib. More than $60 \%$ of patients who received $12 \mathrm{mg}$ once daily had tumor burden shrinkage, and the benefit was long-lasting in several patients. Response to anlotinib was noted in a wide range of tumor types, including renal carcinoma, soft tissue sarcoma, medullary 
Table 3 Pharmacokinetic parameters of anlotinib after a single oral dose of anlotinib capsules in cancer patients and summarized results from dose proportionality assessment

\begin{tabular}{|c|c|c|c|c|c|c|c|c|}
\hline \multirow{2}{*}{$\begin{array}{l}\text { Pharmacokinetic } \\
\text { parameters }\end{array}$} & \multicolumn{4}{|c|}{ Measurement of dose-dependent pharmacokinetics } & \multicolumn{4}{|c|}{ Assessment of dose proportionality } \\
\hline & $\begin{array}{l}5 \mathrm{mg} / \text { person } \\
(n=1)\end{array}$ & $\begin{array}{l}10 \mathrm{mg} / \text { person } \\
(n=4)\end{array}$ & $\begin{array}{l}12 \mathrm{mg} / \text { person } \\
(n=11)\end{array}$ & $\begin{array}{l}16 \mathrm{mg} / \text { person } \\
(n=4)\end{array}$ & $r$ & $P$ & $\begin{array}{l}\text { Slope } \\
(90 \% \mathrm{Cl})\end{array}$ & Conclusion \\
\hline$\overline{C_{\max }, \mathrm{ng} / \mathrm{mL}}$ & 5.8 & $5.8 \pm 2.8$ & $10.5 \pm 2.9$ & $15.8 \pm 3.2$ & 0.629 & 0.003 & $1.12(0.54-1.71)$ & Inconclusive \\
\hline$T_{\max ,} \mathrm{h}$ & 11.0 & $6.0 \pm 4.4$ & $7.3 \pm 3.3$ & $11.0 \pm 8.9$ & - & - & - & - \\
\hline $\mathrm{AUC}_{0-120 h}, \mathrm{~h} \cdot \mathrm{ng} / \mathrm{mL}$ & 411 & $318 \pm 133$ & $617 \pm 194$ & $894 \pm 305$ & 0.465 & 0.045 & $0.81(0.16-1.45)$ & Inconclusive \\
\hline$A \cup C_{0-\infty}, h \cdot n g / m L$ & 687 & $562 \pm 328$ & $1066 \pm 263$ & $1585 \pm 470$ & 0.666 & 0.002 & $1.18(0.62-1.73)$ & Inconclusive \\
\hline$t_{1 / 2}, \mathrm{~h}$ & 102 & $95 \pm 22$ & $116 \pm 47$ & $98 \pm 15$ & - & - & - & - \\
\hline
\end{tabular}

Critical intervals were $0.791-1.209$ for the systemic exposure data of anlotinib from a single oral dose of anlotinib capsules (10-16 mg) in cancer patients. The term $r$ denotes the correlation coefficient. Correlations were statistically significant with $P<0.05$. The term "linear" was concluded statistically if the $90 \%$ confidence interval $(90 \% \mathrm{Cl}$ ) for the slope was contained completely within the critical interval; inconclusive was concluded statistically if the $90 \% \mathrm{Cl}$ lies partly within the critical interval; nonlinear was concluded statistically if the $90 \% \mathrm{Cl}$ was entirely outside the critical interval

$C_{\max }$ maximum plasma concentration, $T_{\max }$ the time taken to achieve the maximum plasma concentration, $A U C_{0-120 h}$ the area under concentration-time curve up to $120 \mathrm{~h}, A \cup C_{0-\infty}$ area under concentration-time curve up to infinity, $t_{1 / 2}$ terminal elimination half-life

thyroid carcinoma, non-small cell lung cancer, colorectal cancer, melanoma, thymic carcinoma, and adenoid cystic carcinoma. This remarkable antitumor activity strongly justified the conduct of phase II clinical trials in those tumor types.

PK assessments in this study demonstrated that anlotinib is rapidly absorbed through the intestine and eliminated slowly with a half-life of $96 \mathrm{~h}$, which resulted in significantly continuous accumulation of anlotinib in plasma over time. This is in agreement with the high frequency of grade 3 toxicity at $10 \mathrm{mg}$ in the $4 / 0$ schedule. To adapt to this PK feature, we changed the administration protocol to the $2 / 1$ schedule, where we observed a 2 -week subchronic rise in plasma concentration with the peak at day 14 , and an apparent decline during the 7-day washout until the beginning of next cycle. This indicated the rational extension of administration interval is more conductive to the establishment of optimal dose for drug with long elimination half-life period.

Based on the toxicity and efficacy profile, anlotinib displayed manageable toxicity and broad-spectrum antitumor potential. The recommended treatment regimen for the following clinical studies is as follows: anlotinib monotherapy, $12 \mathrm{mg}$ per day, on the $2 / 1$ schedule. Based on the promising results in phase I study, a series of phase II clinical trials have been performed and initial efficacy has been observed in several types of solid tumor including colon adenocarcinoma, non-small cell lung cancer, renal clear cell cancer, medullary thyroid carcinoma, and soft tissue sarcoma (details pending publication elsewhere).

\section{Additional file}

Additional file 1: Figure S1. Waterfall plot of best-percent change in target lesions from baseline for the 19 patients who had target lesions on the basis of investigator assessment. (PDF 287 kb)

\section{Abbreviations}

ALT: Alanine aminotransferase; AUC: Area under concentration-time curve; CR: Complete remission; DDR1: Discoidin domain receptor 1; DLT: Doselimiting toxicity; EGFR: Epidermal growth factor receptor; FGF: Fibroblast growth factor; FGFR: Fibroblast growth factor receptor; MTD: Maximum tolerated dose; NCI-CTCAE: National Cancer Institute Common Terminology Criteria for Adverse Events; PD: Progressive disease; PDGFR: Platelet-derived growth factor receptor; PK: Pharmacokinetic; PR: Partial remission; RECIST

1.1: Response Evaluation Criteria In Solid Tumors (version 1.1); SD: Stable disease; TKI: Tyrosine kinase inhibitor; VEGF: Vascular endothelial growth factor; VEGFR: Vascular endothelial growth factor receptor

\section{Acknowledgements}

Not applicable.

\section{Funding}

This study was sponsored by the Jiangsu Chia-tai Tianqing Pharmaceutical Co., Ltd. The funders had no role in study design, data collection and analysis, decision to publish, or preparation of the manuscript.

Availability of data and materials

Due to our internal policy, raw data cannot be shared.

\section{Authors' contributions}

YS, WN, JW, YC, and CL designed the research and/or analyzed the data. YS, FD, $C D, S L, J W, Y H$, and $Y C$ provided the safety and antitumor properties data. WN, LL, FW, and CL provided the pharmacokinetics data. YS, WN, YC, and CL wrote the manuscript. All authors read and approved the final manuscript.

\section{Competing interests}

The authors declare that they have no competing interests.

\section{Consent for publication}

The consent to publish has been obtained from the participant to report individual patient data.

\section{Ethics approval and consent to participate}

The study protocol was approved by the institutional review board at the Cancer Hospital, Chinese Academy of Medical Sciences, and PUMC in accordance with the Declaration of Helsinki. Patients provide informed consent authorizing the use of their personal information for research purposes.

\section{Author details}

${ }^{1}$ Department of Medical Oncology, Cancer Hospital, Chinese Academy of Medical Sciences and PUMC, Beijing 100021, China. ${ }^{2}$ The State Key Laboratory of Drug Research, Shanghai Institute of Materia Medica, Chinese Academy of Sciences, Shanghai 201203, China. ${ }^{3}$ The VIPII Gastrointestinal Cancer Division of Medical Department, Peking University Cancer Hospital and Institute, Beijing 100142, China. ${ }^{4}$ School of Public Health, Nanjing Medical University, Nanjing, China. 
Received: 6 July 2016 Accepted: 22 September 2016

Published online: 04 October 2016

\section{References}

1. Hanahan D, Weinberg RA. Hallmarks of cancer: the next generation. Cell. 2011;144(5):646-74.

2. Hanahan D, Weinberg RA. The hallmarks of cancer. Cell. 2000;100(1):57-70.

3. Strumberg D, Richly H, Hilger RA, Schleucher N, Korfee S, Tewes M, et al. Phase I clinical and pharmacokinetic study of the Novel Raf kinase and vascular endothelial growth factor receptor inhibitor BAY 43-9006 in patients with advanced refractory solid tumors. J Clin Oncol. 2005;23(5):965-72

4. Faivre S, Delbaldo C, Vera K, Robert C, Lozahic S, Lassau N, et al. Safety, pharmacokinetic, and antitumor activity of SU11248, a novel oral multitarget tyrosine kinase inhibitor, in patients with cancer. J Clin Oncol. 2006;24(1):25-35.

5. Mross K, Frost A, Steinbild S, Hedbom S, Büchert M, Fasol U, et al. A phase I dose-escalation study of regorafenib (BAY 73-4506), an inhibitor of oncogenic, angiogenic, and stromal kinases, in patients with advanced solid tumors. Clin Cancer Res. 2012;18(9):2658-67.

6. Huang L, Huang Z, Bai Z, Xie R, Sun L, Lin K. Development and strategies of VEGFR-2/KDR inhibitors. Future Med Chem. 2012:4(14):1839-52.

7. Turner N, Grose R. Fibroblast growth factor signalling: from development to cancer. Nat Rev Cancer. 2010;10(2):116-29.

8. Knights V, Cook SJ. De-regulated FGF receptors as therapeutic targets in cancer. Pharmacol Ther. 2010;125(1):105-17.

9. Wesche J, Haglund K, Haugsten EM. Fibroblast growth factors and their receptors in cancer. Biochem J. 2011:437(2):199-213.

10. Turner N, Pearson A, Sharpe R, Lambros M, Geyer F, Lopez-Garcia MA, et al. FGFR1 amplification drives endocrine therapy resistance and is a therapeutic target in breast cancer. Cancer Res. 2010;70(5):2085-94.

11. Elbauomy ES, Green AR, Lambros MB, Turner NC, Grainge MJ, Powe D, et al. FGFR1 amplification in breast carcinomas: a chromogenic in situ hybridisation analysis. Breast Cancer Res. 2007;9(2):R23.

12. Matsumoto K, Arao T, Hamaguchi T, Shimada Y, Kato K, Oda I, et al. FGFR2 gene amplification and clinicopathological features in gastric cancer. $\mathrm{Br} J$ Cancer. 2012;106(4):727-32.

13. Deng N, Goh LK, Wang H, Das K, Tao J, Tan IB, et al. A comprehensive survey of genomic alterations in gastric cancer reveals systematic patterns of molecular exclusivity and co-occurrence among distinct therapeutic targets. Gut. 2012;61(5):673-84.

14. Ashton S, Song YH, Nolan J, Cadogan E, Murray J, Odedra R, et al. Aurora kinase inhibitor nanoparticles target tumors with favorable therapeutic index in vivo. Sci Transl Med 2016; 8(325):325ra17.

15. Wang C, Chen J, Cao W, Sun L, Sun H, Liu Y. Aurora-B and HDAC synergistically regulate survival and proliferation of lymphoma cell via AKT, mTOR and Notch pathways. Eur J Pharmacol. 2015;779:1-7.

16. Kakiuchi-Kiyota S, Lappin PB, Heintz C, Brown PW, Pinho FO, Ryan AM, et al. Expression of proto-oncogene CFMS protein in lung, breast, and ovarian cancers. Appl Immunohistochem Mol Morphol. 2014:22(3):188-99.

17. Ambrogio C, Gómez-López G, Falcone M, Vidal A, Nadal E, Crosetto N, et al. Combined inhibition of DDR1 and Notch signaling is a therapeutic strategy for KRAS-driven lung adenocarcinoma. Nat Med. 2016;22(3):270-7.

18. Beck J, Procopio G, Bajetta E, Keilholz U, Negrier S, Szczylik C, et al. Final results of the European Advanced Renal Cell Carcinoma Sorafenib (EU-ARCCS) expanded-access study: a large open-label study in diverse community settings. Ann Oncol. 2011;22(8):1812-23.

19. Porta C, Gore ME, Rini BI, Escudier B, Hariharan S, Charles LP, et al. Long-term safety of sunitinib in metastatic renal cell carcinoma. Eur Urol. 2016;69(2):345-51.

20. Afonso FJ, Anido U, Fernández-Calvo O, Vázquez-Estévez S, León L, Lázaro $M$, et al. Comprehensive overview of the efficacy and safety of sorafenib in advanced or metastatic renal cell carcinoma after a first tyrosine kinase inhibitor. Clin Transl Oncol. 2013;15(6):425-33.

21. Stadler WM, Figlin RA, McDermott DF, Dutcher JP, Knox JJ, Miller WH, et al Safety and efficacy results of the advanced renal cell carcinoma sorafenib expanded access program in North America. Cancer. 2010;116(5):1272-80.

22. Gore ME, Szczylik C, Porta C, Bracarda S, Bjarnason GA, Oudard S, et al. Safety and efficacy of sunitinib for metastatic renal-cell carcinoma: an expanded-access trial. Lancet Oncol. 2009;10(8):757-63.

23. Qi WX, Shen Z, Tang LN, Yao Y. Risk of arterial thromboembolic events with vascular endothelial growth factor receptor tyrosine kinase inhibitors: an up-to-date meta-analysis. Crit Rev Oncol Hematol. 2014:92(2):71-82.

\section{Submit your next manuscript to BioMed Central and we will help you at every step:}

- We accept pre-submission inquiries

- Our selector tool helps you to find the most relevant journal

- We provide round the clock customer support

- Convenient online submission

- Thorough peer review

- Inclusion in PubMed and all major indexing services

- Maximum visibility for your research

Submit your manuscript at www biomedcentral.com/submit
C BioMed Central 